
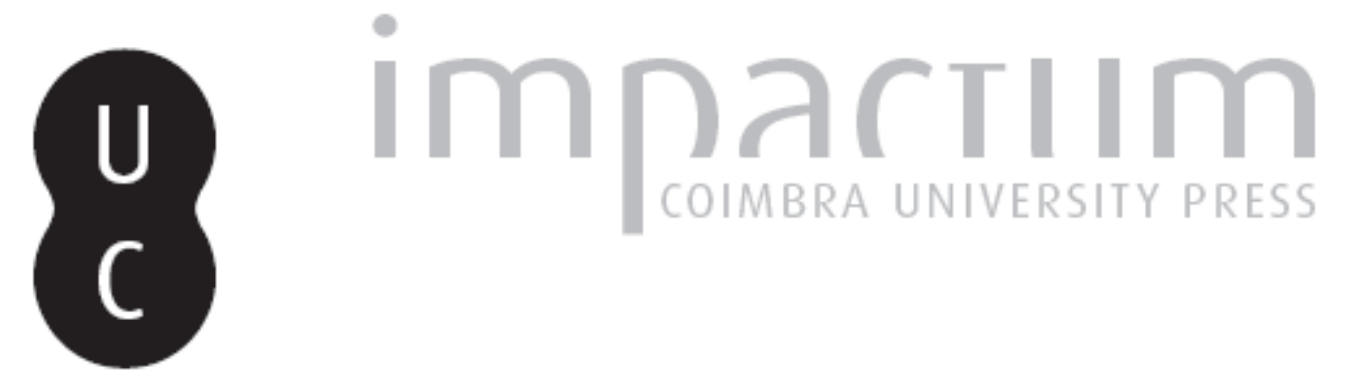

\title{
Deslocamentos sociais e formação discursiva do sem-terra
}

Autor(es): $\quad$ Fernandes, Cleudemar Alves

Publicado por: Faculdade de Letras da Universidade de Coimbra

URL persistente:

URI:http://hdl.handle.net/10316.2/32739

DOI:

DOI:http://dx.doi.org/10.14195/0870-4112_7_10

Accessed : $\quad$ 26-Apr-2023 12:30:46

A navegação consulta e descarregamento dos títulos inseridos nas Bibliotecas Digitais UC Digitalis, UC Pombalina e UC Impactum, pressupõem a aceitação plena e sem reservas dos Termos e Condições de Uso destas Bibliotecas Digitais, disponíveis em https://digitalis.uc.pt/pt-pt/termos.

Conforme exposto nos referidos Termos e Condições de Uso, o descarregamento de títulos de acesso restrito requer uma licença válida de autorização devendo o utilizador aceder ao(s) documento(s) a partir de um endereço de IP da instituição detentora da supramencionada licença.

Ao utilizador é apenas permitido o descarregamento para uso pessoal, pelo que o emprego do(s) título(s) descarregado(s) para outro fim, designadamente comercial, carece de autorização do respetivo autor ou editor da obra.

Na medida em que todas as obras da UC Digitalis se encontram protegidas pelo Código do Direito de Autor e Direitos Conexos e demais legislação aplicável, toda a cópia, parcial ou total, deste documento, nos casos em que é legalmente admitida, deverá conter ou fazer-se acompanhar por este aviso.

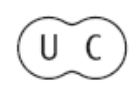




\section{Sociedade em Tumulto}

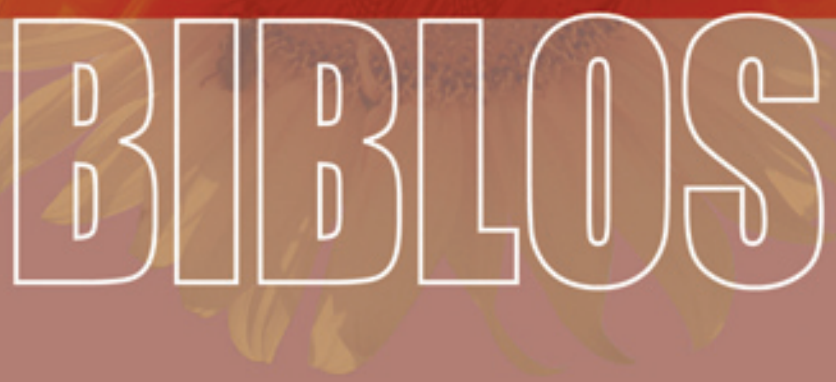

REVISTA DA FACULDADE DE LETRAS

UNIVERSIDADE DE GOIMBRA 
Biblos, n. s. VII (2009) 219-240

Cleudemar Alves Fernandes

Universidade Federal de Uberlândia

\section{DESLOCAMENTOS SOCIAIS E FORMAÇÃO DISCURSIVA DO SEM-TERRA}

\section{Resumo}

Esta pesquisa procura explicar a formação discursiva de um grupo de sem-terra do Triângulo Mineiro - Brasil, baseada na interacção desses sujeitos com outros grupos sociais contrários ou favoráveis ao "Movimento de Luta pela Terra". O material usado nesta análise foi obtido em entrevistas gravadas in loco e caracteriza-se pela espontaneidade e interacção entre o entrevistador e os interpelados. A análise do discurso foca-se nos deícticos espaciais e temporais, levando em consideração que estas categorias linguísticas se revelam através da interacção em diferentes momentos e localizações sociofísicas, revelando a construção da sua história além da sua formação discursiva e ideológica. A teoria em que se baseia este estudo é a da perspectiva francesa da Análise do Discurso, levada a cabo nas condições em que o discurso é produzido. O Discurso é entendido como o resultado de uma interacção social dos sujeitos envolvidos e, assim, permite a interacção. A interacção verbal em sociedade, no caso dos sem-terra, tendo em consideração a sua produção físico-sociais (que envolve também a produção do discurso), é discutida na sua formação ideológica e discursiva, que são práticas únicas no quotidiano desses sujeitos.

Palavras-chave: formação discursiva, sem-terra, interacção social.

\section{Abstract}

This study seeks to explain the discursive formation of a group of landless people of the Minas Triangle, in Brazil, based on the interaction of these subjects with other social groups who are for or against the "Movement of Struggle for Land." The material used in the analysis was obtained from interviews that were recorded at the site, and is characterized by spontaneity and interaction between the interviewer and the respondents. The analysis of the discourse focuses on spatial and temporal deictics, taking into consideration the fact that these linguistic categories emerge from interaction at different times 
and socio-physical locations, revealing the construction of their history as well as their discursive and ideological formation. The theoretical underpinning of this study is provided by the French approach of Discourse Analysis, and the analysis was carried out based on the conditions in which the discourse was produced. Discourse is understood as a result (product) of social interaction of the subjects involved and, thus, enables interaction. The article discusses the ideological and discursive formation of the verbal social interaction of landless people, taking into account its socio-historical production (which also involves discourse production).

Keywords: Discursive Formation; Landless People; Social Interaction.

\section{INTRODUÇÃO}

O estudo que ora se apresenta destina-se à análise da formação discursiva de um grupo de Sem-Terra do Triângulo Mineiro - região locazida no interior do Brasil. O surgimento desses sujeitos e sua organização em grupos sociais no cenário nacional brasileiro apresentam-se como um processo decorrente de transformações histórico-sociais ocorridas no país e apreendidas na/pela linguagem. Para este estudo, serão considerados os processos de transformação históricosocias e os fenômenos lingüísticos que os integram, e suas implicações nos funcionamentos dos discursos constituídos por aspectos sócio-ideológico-históricos, posto que os Sem-Terra e, conseqüentemente os discursos que os envolvem, surgem em contextos de trasformações, conforme mostraremos.

Metodologicamente, em um primeiro momento, será apresentada a noção de formação discursiva seguida de breves apontamentos sobre a recorrência aos dêiticos como recorte lingüístico para analisar o discurso; em seguida, será focalizada a existência dos sujeitos nos espaços urbano e rural, nos quais, constitutivamente, interagem. O modelo teórico norteador deste estudo advém da Análise do Discurso de linha francesa, que se volta para os aspectos históricos e ideológicos próprios ao funcionamento e formação dos discursos. $\mathrm{O}$ material tomado para análise resulta de entrevistas, documentadas por Silva (1996) e (re) organizadas por Fernandes (2001), com sujeitos integrantes do Movimento de Luta pela Terra, na região supracitada, cuja composição consta de vinte e cinco (25) entrevistas com sujeitos acampados. A análise será realizada a partir da dêixis discursiva. Serão identificados os dêiticos espaciais e temporais empregados ao longo 
das entrevistas uma vez que essas categorias lingüísticas possibilitam apreender os sujeitos em diferentes espaços físico-sociais, e verificar suas (trans) formações discursivas. Após a identificação dessas categorias lingüísticas, serão recortados alguns fragmentos em que estão empregadas para, então, proceder à análise visando a abordar os aspectos históricos, ideológicos e sociais próprios à formação discursiva do Sem-Terra, tendo em vista a produção de sentidos do/ no discurso.

A noção de formação discursiva, conceito primordial para este estudo, coloca em pauta um conjunto de conceitos, às vezes, conflitantes, mas necessários à sua compreensão e formulação, resulta de um entrecruzamento entre História e Lingüística e constitui lugar relevante para a Análise do Discurso. Discorrer sobre esse conceito implica refletir sobre as condições de possibilidade dos discursos, considerando as contradições socioideológicas que lhes são constitutivas. Quanto à análise do discurso do Sem-Terra especificamente, considerar-se-á, inicialmente, a interação dos sujeitos Sem-Terra com outros sujeitos e grupos favoráveis ou contrários ao movimento, para, então, evidenciar a formação do discurso do Sem-Terra pela interação social estabelecida com diferentes sujeitos sociais, com diferentes formações discursivas e ideológicas, com as quais se confrontam.

\section{Da Noção de Formação Discursiva}

O discurso, ao ser produzido e interpretado, constitui uma ação social e é sempre ideologicamente marcado. Assim, a noção-conceito de formação discursiva (FD)

começa a fazer explodir a noção de máquina estrutural fechada na medida em que o dispositivo da FD está em relação paradoxal com seu "exterior": uma FD não é um espaço estruturalmente fechado, pois é constitutivamente "invadido" por elementos que vêm de outro lugar (isto é, de outras FD) que se repetem nela, fornecendo-lhe suas evidências discursivas fundamentais (PÊCHEUX, 1990, p. 314).

Uma formação discursiva refere-se ao que se pode dizer somente em determinada época e espaço social, ao que tem lugar e realização a partir de condições de produção específicas, historicamente definidas. Conforme acrescenta Foucault (1995, p. 31), 
trata-se de compreender o enunciado na estreiteza e singularidade de sua situação; de determinar as condições de sua existência, de fixar seus limites da forma mais justa, de estabelecer suas correlações com os outros enunciados a que pode estar ligado, de mostrar que outras formas de enunciação exclui.

Uma formação discursiva caracteriza-se pela existência de um conjunto semelhante de objetos e enunciados que os descrevem, pela possibilidade de explicitar como cada objeto do discurso tem, nela, o seu lugar e sua regra de aparição, e como as estratégias que a engendram derivam de um mesmo jogo de relações. Trata-se, como observa Robin (1997), de compreender as condições de possibilidade do discurso, como um dizer tem espaço em um lugar e em uma época específica.

Como formação discursiva reflete, também, formação social, retoma-se uma heterogeneidade própria à coexistência de diferentes forças sociais. A dominância de um modo de produção representa o primado da vida econômica, mas a pobreza, por sua vez, implica formação social, porque na pobreza também há lutas econômicas e políticas.

Os aspectos ideológicos, e políticos, no discurso, apresentam-se semanticamente relevantes, pois refletem, na interação entre os sujeitos, o lugar histórico-social de onde o discurso é produzido. A ação política, em forma de discurso, apresenta valores ideológicos na construção de determinados espaços sociais. Nessa perspectiva, as relações de poder constróem-se e as representações de poder confrontam e alteramse, mudando, conseqüentemente, o lugar de onde vozes emitem enunciações, de onde os discursos são produzidos. As alterações político-ideológicas nos discursos decorrem da mudança de sujeitos em cena, ou da transformação dos sujeitos na linha do tempo, o que implica mudanças no espaço social. Na verdade, novas perspectivas políticas e ideológicas, que provocam o surgimento de um novo cenário sociocultural, são aspectos inerentes à formação de um "novo" discurso.

Ao referir-se às práticas discursivas, refere-se, também, a práticas sociais, visto que o discurso envolve condições histórico-sociais de produção. Essa observação torna oportuno refletir sobre as condições de produção dos discursos que incluem o contexto sócio-histórico e ideológico, incluindo, igualmente, as condições de produção de bens materiais e a (re)produção das próprias condições de produção.

O lugar histórico-social em que os sujeitos enunciadores de determinado discurso encontram-se envolve o contexto e a situação e 
intervém a título de condições de produção do discurso. Não se trata da realidade física e sim de um objeto imaginário socioideológico.

Diretamente vinculadas às condições de produção de discurso e de ideologia, as formações discursivas implicam, ao mesmo tempo em que resultam de, (trans)formações sociais e formações ideológicas. As formações discursivas são reconhecidas pela presença, ou melhor, pela materialização de ideologias, de formações ideológicas, sem, contudo, haver equivalência, ou correspondência entre formação discursiva e formação ideológica.

Acerca das formações discursivas, Pêcheux (1990) observou que uma formação discursiva é invadida por elementos oriundos de outras formações discursivas, de outros lugares. $\mathrm{E}$ as palavras têm seus sentidos segundo a inscrição ideológica de quem as enuncia, do lugar que emerge a enunciação. É segundo as posições dos sujeitos que os sentidos se manifestam, em relação às formações ideológicas nas quais essas posições se inscrevem.

Nessa perspectiva, as ideologias manifestam-se em atitudes, comportamentos e linguagem e constituem práticas discursivas integrando as formações sociais e discursivas.

O conceito de formação discursiva, revisitado pelos historiadores do discurso, ganha ênfase, no que concerne ao sujeito e à materialidade lingüística, apreendida para análise. Guilhaumou (2005, p 112), ao discorrer sobre as transformações sofridas por esse conceito no interior da Análise do Discurso, de seu aparecimento aos dias atuais, ressalta: $a$ noção de formação discursiva deixa, de agora em diante, o lugar para o sujeito empírico, um sujeito ao mesmo tempo ancorado em blocos de realidade e tomado em seus efeitos discursivos, aspectos que, também, serão considerados neste estudo.

Todas essas questões são constituídas por um movimento interacional no qual os sujeitos se constituem. Analisar os discursos requer fazer aparecer os aspectos referentes à forma de existência social dos sujeitos tendo em vista os aspectos lingüísticos e ideológicos que engendram o percurso interacional nas formações discursivas, na formação e transformação desses sujeitos e do grupo social que constituem.

A partir da recorrência aos conceitos mencionados, isto é, pelas noções de discurso, de formação discursiva e ideológica, pelas condições de produção, reitera-se um caráter de mutabilidade dos discursos e dos sujeitos, marcados por conflitos próprios às tensões sociais, que, na História, possibilita as formações e transformações sociais e discursivas. 
São justamente esses os aspectos a serem explicitados na análise do discurso do Sem-Terra.

\section{A Dêixis no discurso}

Para procedermos ao estudo do discurso do Sem-Terra, abordaremos os dêiticos espaciais e temporais como categorias selecionadas na materialidade lingüística como ponto de partida para a análise. Considerando que pessoa, espaço e tempo são indissociáveis no âmbito do discurso, essas categorias lingüísticas foram escolhidas para a análise por possibilitarem o resgate do percurso interacional, da história dos sujeitos entrevistados, situando-os, cronológica e topograficamente, em diferentes espaços físicos e sociais e em diferentes momentos nos quais interagiram e interagem. A dêixis possibilita, no discurso, além de situar os sujeitos em diferentes tempos e espaços que constituem a cena enunciativa, evidenciar-lhes a heterogeneidade constitutiva. Ao analisar o discurso, tendo em vista as movências sociais dos sujeitos e dos discursos, buscar-se-á compreender a constituição social do sujeito denominado Sem-Terra, centrando-se em sua formação discursiva, ou formações discursivas.

Semanticamente, os dêiticos integram, na linguagem, a noção de referente acrescida às noções de significado e significante. Quando um enunciado contém um dêitico qualquer, este não tem em si um conteúdo semântico; o conteúdo semântico encontra-se no que é referido pelo dêitico, logo, integra o enunciado conferindo sentidos ao discurso. Como argumenta Lahud (1979, p. 68), “o conhecimento das circunstâncias que acompanham as palavras torna-se, então, uma condição necessária para a 'exata compreensão' do pensamento expresso contendo dêiticos". Nota-se, ainda, que a apresentação do objeto, pelo dêitico, pode referir-se às circunstâncias do próprio discurso.

A significação de um dêitico, pela estrutura sintática no enunciado, remete às relações que constituem os sentidos desses elementos lingüísticos no discurso. Para Alston (apud Lahud, 1979, p. 68), "trata-se de palavras que, embora tenham uma significação constante, mudam sistematicamente, de referência conforme as mudanças nas condições de elocução".

A análise do discurso, a partir dos dêiticos, deve considerar a inserção do sujeito no próprio discurso, nos lugares e tempos referidos e resgatados por essas categorias linguiísticas, a forma de existência dos sujeitos, integrando os sentidos produzidos no discurso pelas referências 
a espaço e tempo, visto que esses elementos não são apenas físicos, são essencialmente sociais.

A análise, a seguir, será realizada a partir da identificação e seleção dos dêiticos espaciais e temporais, conforme anunciou-se. Esta seleção compreende uma micro-análise, em que se identificam e categorizam tais categorias lingüísticas para, então, proceder-se à macro-análise. Esta apresenta um caráter interpretativo, tendo em vista o conteúdo semântico, e destina-se à reflexão das significações histórico-sociais e ideológicas possíveis pela interação entre os sujeitos, na negociação de sentidos constitutiva dos discursos que desencadeiam a formação do discurso do Sem-Terra.

Para a análise a seguir, trabalhar-se-á com recortes de fragmentos do discurso, nos quais os elementos pré-selecionados se encontram empregados. A noção de recorte é introduzida por Orlandi et al. (1989, p. 36) como "unidade discursiva [...] fragmentos correlacionados de linguagem [...] um fragmento da situação discursiva", definido por associações semânticas, acrescenta Voese (1998).

Os dêiticos supracitados são tomados como os elementos que possibilitam uma imersão no discurso, marcam e delimitam momentos importantes para abordar o conteúdo semântico e evidenciar o que nele pode estar posto, os sentidos produzidos. Considerando que os dêiticos em si não têm conteúdo semântico, mergulhar-se-á nas condições de produção desses sujeitos, nos aspectos discursivos e ideológicos que possibilitam observar e resgatar as formações discursivas que lhes são próprias, porquanto os dêiticos não efetuam somente referência indicando o lugar e o tempo, reportam-se ao evento, ao tipo de encontro, à organização histórico-social.

Os dêiticos espaciais serão interpretados observando-se a referência à posição, ao lugar que o enunciador ocupa e/ou ocupou em diferentes espaços físico-sociais. Tem-se uma localização absoluta (lugar determinado em que se encontra) e uma localização contextual, "que se apóia em um elemento do contexto linguiístico" (Maingueneau, 1995, p. 30). Esses dêiticos aparecem no discurso como determinantes nominais (demonstrativos) ou como advérbios; evidenciam-se pelas informações fornecidas pelo contexto, tendo em vista a localização do corpo do locutor. Já os temporais originam-se no momento presente da enunciação, "momento que corresponde ao presente lingüístico". Porém, encontram-se também no discurso as localizações temporais absolutas (data ou momento específico) e as "que se apoiam em uma referência para que sejam interpretadas" (Maingueneau, 1995, p. 31). 
No discurso, esses dêiticos podem ser categorizados como advérbios ou como um grupo proposicional.

Os sujeitos entrevistados, ao enunciar, irão retroagir no tempo e no espaço, percorrendo, em retrospectiva, o caminho de sua constituição como o sujeito do momento presente da entrevista: um sujeito situado em um tempo e em um espaço histórico-sociais específicos. O tempo e o espaço serão elementos não exteriores ao discurso, mas partes integrantes do discurso.

Os fragmentos recortados para a análise serão numerados e seguidos da indicação do sujeito enunciador, conforme consta no Banco de Dados da pesquisa (Cf. FERNANDES, 2001).

\section{O Lavrador na cidade: o sujeito destituído}

Um breve olhar para a história dos movimentos dos trabalhadores rurais Sem-Terra, iniciados no Brasil oficialmente como uma entidade na década de 1980, explicita seus integrantes como sujeitos destituídos de seu espaço original - o rural -, visto que esse espaço social também foi desconstruído em decorrência das mudanças ocorridas nas condições de produção ${ }^{1}$. Diante disso, esses sujeitos procuraram reconstituir-se socialmente na cidade, local para onde emigraram, sabendo-se que as condições de produção implicam a produção do trabalho, do alimento, de ideologia e de discurso, e encontram-se em constantes transformações.

Diante dessas observações, ressalta-se que a cidade apresenta-se como um espaço de deslocamento social, no qual não conseguem adaptar-se às novas formas de trabalho, sendo o trabalho o responsável pelo restabelecimento desses sujeitos sob condições de existência satisfatórias. Nesse novo ambiente, a interação desses sujeitos, entre si e com diferentes segmentos sociais, possibilitou formações discursivas e ideológicas que resultam na existência do Sem-Terra na condição de grupos socialmente organizados, em nível nacional.

Considerando que a dêixis discursiva tem a função de situar os sujeitos em espaços e tempos em que interagiram e interagem, mediante

${ }^{1}$ Os Movimentos dos trabalhadores rurais Sem-Terra tiveram como o maior dos fatores responsáveis por seu surgimento a expropriação do trabalhador rural da terra em decorrência da modernização da agricultura e criação de agroindústrias, no Brasil, a partir dos anos 1960. Com a presença de maquinaria na execução de atividades agrícolas, grandes contingentes de trabalhadores rurais viram-se expulsos da terra, onde, mesmo não sendo proprietários, dispunham de meios de produção para a subsistência. 
a análise do discurso desses sujeitos, conhecer-se-á seu mundo social, evidenciando-lhes as formações discursivas próprias à constituição do Sem-Terra.

Nessa perspectiva, a leitura do fragmento a seguir coloca em evidência as condições existenciais do sujeito migrante do espaço rural para o urbano.

\section{Fragmento 1}

A gente ... meu marido trabalhava pra-qui pra-li ... quando achava um dia de sirviço trabaiava quando num tinha tinha que ficá im casa né ... aí a situação foi apertano e saiu um negoço de reforma agrária ... a gente reunia ia sempre nas reunião ... um grupo piqueno de gente ... aí ele decidiu que nois vinha e eu também decidi a vim junto nois dois é naquele dia pra luta ... aí a gente entrô dentro das terra ... trinta e treis família é e tô aqui até hoje firme na luta (S2/p.19)

Consoante às observações arroladas anteriormente acerca da dêixis, nota-se que os dêiticos espaciais pra-qui pra-li, empregados na primeira linha do fragmento, demonstram um conflituoso processo caracterizado pela instabilidade social do sujeito em questão. Aspecto resultante da falta de um trabalho fixo, que lhe assegurasse a definição de sua condição social, que lhe possibilitasse uma maneira de pertença à sociedade, da qual, mesmo estando em presença física, encontra-se excluído, sendo a exclusão uma forma de participação.

Essa impossibilidade do restabelecimento social na cidade, somada à destituição, ao apagamento do espaço original desse sujeito, resulta em mudanças político-ideológicas, provocadoras de uma renovação dos sujeitos, sob novas perspectivas para a ação. Como último recurso para o restabelecimento social, o enunciador aponta seu ingresso ao Movimento de Luta pela Terra. A cidade, mesmo não oferecendo trabalho, condições de produção material a esse sujeito, possibilitoulhe a interação para, juntamente com seus similares, estruturarem-se como grupo e projetarem-se rumo à busca da reconstrução de seu mundo e, conseqüentemente, à reconstrução daqueles sujeitos anulados em suas formas de existência. Nesse momento, ao efetuar referência à pessoa do discurso, o enunciador emprega, consecutivamente, nós, eu e a gente. $\mathrm{O}$ "eu" remete a si, quando decidiu integrar o movimento; o "nós" reporta-se à voz do grupo, do qual o sujeito enunciador participa; "a gente", também se referindo ao grupo, especifica-o: trinta e três famílias. 
A referência ao ingresso à luta aponta-a como um espaço social com formas de organização próprias, o qual passou a integrar. Ainda se referindo à adesão ao movimento, o enunciador emprega o dêitico $a q u i$, ao qual são atribuídas duas funções concomitantes. A primeira, de situar o sujeito no presente da entrevista; a segunda, de informar acerca do tempo de sua permanência no acampamento, na terra, espaço físico ocupado pelo grupo.

Ao refletirem sobre as formas de existência na cidade, os sujeitos entrevistados, em sua quase totalidade, detiveram-se a assinalar as dificuldades materiais advindas da impossibilidade de obtenção de trabalho e, ainda, pelo contraste estabelecido entre o campo e a cidade, enumeraram o quanto os gastos são mais acentuados neste último espaço. Esses aspectos, já apontados por Silva (1996), podem ser notados no fragmento 2 , a seguir.

\section{Fragmento 2}

as pessoa que tivé na cidade que ... é percurá a luta né percurá ... lutá pela ... pela terra memo né pa saí do ... do sufoco da cidade né ... e caçá um jeito de í pa terra memo ... caçá um jeito de trabaiá ... porque acho que pro ... pa pobre ... é ... tem que sê fazenda memo ... tem que sê terra (risos) ... cidade num dá muito certo ... dá camisa pa ninguém não... (S10/p.108)

Nesse fragmento, nota-se um contraste entre os diferentes lugares, ressaltando os benefícios que a obtenção da terra lhes traria. Por possibilitar as condições de produção, em especial, a produção do alimento, a conquista desse novo espaço possibilitaria a (re)construção social dos sujeitos. Nesse fragmento, o enunciador argumenta em favor do abandono da cidade, considerando a fazenda - terra - como lugar propício às suas possibilidades de trabalho e produção. Há, portanto, um movimento circular na tentativa de estabelecimento social (campo - cidade - campo).

Esse percurso oferece a esses sujeitos diferentes formas de constituírem e destituírem-se. A negação à cidade em favor da luta por um pedaço de terra deve-se às formações ideológicas resultantes da interação estabelecida na cidade. No fragmento 2 , quando o enunciador argumenta em favor das pessoas de classe baixa rejeitarem a vida urbana em prol da conquista da terra, pode-se considerar que esse discurso é marcado politicamente, pois visa a promover a adesão ao movimento 
e, conseqüentemente, fortalecê-lo pelo aumento do número de sujeitos envolvidos.

Se, por um lado, houve perda das condições de produção, das condições de trabalho no ambiente rural, desencadeando a emigração, por outro, essas condições sequer figuram em seu novo espaço social, o urbano.

A cidade apresenta-se também como o lugar para o fracasso, para a exposição da incapacidade. Esses sujeitos não se adaptam nem mesmo à condição de mão de obra desqualificada, pois são, em sua grande maioria, analfabetos, ou possuem um nível de escolaridade baixíssimo. A impotencialidade para o trabalho citadino, e sua escassez, traduz-se em exclusão social, podendo levá-los à peregrinação, à marginalidade e, em última análise, à miséria, como se nota no fragmento seguinte.

Fragmento 3

que ele não consegue imprego na cidade aí ... im Santa Vitória ... a gente num consegue imprego pra gente de crasse baxa ... assim pu que o povo dá mais ... o prefeito dá mais apoio pra quem tem já uma ... um poquim ... pobre num ... é custoso pa arrumá serviço lá (S20/p.198)

Segundo a perspectiva do enunciador, a cidade é o lugar ideal para a marginalização de seu grupo, pois o discrimina, imputa a esses sujeitos um sentimento de não pertença à sociedade, devido à exclusão de uma classe, da qual participa. Atingidos pelo status socialmente atribuído a eles, deslocam novamente no espaço físico visando à reconstrução do espaço social.

No presente da entrevista, ao efetuar referência à cidade, o enunciador assume um olhar distanciado, distância explicitada pelo dêitico lá, cujo conteúdo semântico-discursivo separa o sujeito em termos de espaço físico, separando-o, conseqüentemente, daquela forma de existência social, já experimentada e, por isso, sabida amarga. Esse distanciamento colocado pelo enunciador assegura-lhe nova forma de pertença à sociedade, retificando os seus valores socioculturais e restabelecendo a dignidade.

Como acampados, distantes da vida urbana, os entrevistados acreditam avaliar melhor as suas condições existenciais na cidade, justamente por assumirem um novo olhar devido ao distanciamento estabelecido, como pode ser verificado no fragmento abaixo. 
Fragmento 4

esses dia eu ainda falei aqui no acampamento ... é tanta pobreza tanta miséria ... se tivesse corage de enchê uns caminhão e vim pra terra eles cumia mió ... que eu acho que nunca vai chegá o ponto de falá nois hoje nois num vai podê cumê pu que num tem cumê ... que seje mandioca nois tem ... e nois sempre teve né ... desde o Capãozim nois tem ... e a gente tem um ... cê sabe que é aqui depois que a gente tá tem mais fartura pra levá pra casa do que quando a gente tava lá ... pu que lá cê trabaiava se ocê comprasse um quilo de carne cê num dava conta de comprá um quilo de verdura ... e um litro de leite cê num dava conta todo dia ... meu netim mes foi criado ... eu comprava dois litro de leite pa dá puma semana ... que num dava conta de compra mais ... e aí depois que a gente tá aqui ... o ano passado eu fiz farinha ... porvilho ... tem lata de porvilho lá im casa cheinha ... de mandioca do acampamento ... vô levo verdura ... e eu sei lá ... eu acho ... que se eles acreditasse e viesse pa luita eles num passava fome mais não ... mais eles num aquerdita ... eles acha mió ficá lá na cidade que vim (S20/p.208)

A vida desses sujeitos é marcada pela miséria, pela penúria resultante da dificuldade para a obtenção de alimento; a propósito, é a busca das condições alimentares, de uma mesa farta, a necessidade do fomento para toda forma de subsistência social, o que mais impulsiona os sujeitos à luta. A luta pelo alimento, pelo sustento, pode significar a busca do direito de sonhar, sonhar com formas de viver, sonhar com a existência da felicidade, e, talvez sonhando, ser um pouco feliz. Em releitura de Marx, De Certeau (1982, p. 24) reafirma:

para se viver é necessário, antes de tudo, beber, comer, morar, vestir-se e ainda algumas outras coisas. O primeiro fato histórico [...] é, pois, a produção [...] dos meios que permitem satisfazer essas necessidades, a produção [...] da própria vida material, e isto é um fato histórico [...] uma condição fundamental [...] de toda a história, que se deve, hoje como há milhares de anos, preencher dia após dia.

A cidade é considerada como o lugar da construção do sujeito miserável, o lugar propício à proliferação da fome e, por isso, rejeitado. Nesse sentido, observe-se a dêixis discursiva no fragmento acima.

A primeira referência espacial - aqui - situa o sujeito no acampamento, lugar onde se encontra e de onde reflete sobre as condições de produção em outros espaços por que passou. Logo em 
seguida, refere-se novamente a espaço por meio da locução adverbial de lugar pra terra. Esse lugar, considera o entrevistado, possibilita-lhes condições de produção melhoradas, assegurando-lhes a alimentação, resguarda o sustento necessário para projetarem formas de pertença à sociedade. Por meio dessas referências a espaços, os sujeitos situamse sob diferentes formas existenciais em diferentes momentos. As indicações temporais, por sua vez, explicitam os contextos sociais. Nesse sentido, encontra-se no discurso a referência ao tempo pelo advérbio hoje, que, além de indicar o presente da entrevista, explicita as condições sociais do sujeito nesse momento. Quando o sujeito enuncia: eu acho que nunca vai chegá o ponto de falá nois hoje nois num vai podê cumê pu que num tem cumê, a negação da possibilidade de faltar a alimentação à mesa permite inferir tal ocorrência enquanto estiveram buscando se estabelecer socialmente na cidade, fato confirmado ao final do fragmento. Ao fazer essa negação, o sujeito firma-se em suas próprias experiências durante o tempo de permanência no acampamento. Esse período aponta para novas condições de produção, conforme o enunciador enumera, sempre se centrando na produção alimentícia e em suas possibilidades de reprodução. O dêitico espacial aqui é (re) utilizado na sexta linha do fragmento, a partir do qual o sujeito reafirma ser esse espaço a possibilidade de reconstrução social, não apenas para os sujeitos que ali se encontram, mas para todos que existem em condições similares às suas, tendo em vista a certeza de que o fomento para a vida (a alimentação), ainda que sob medidas básicas mínimas, não irá faltar.

Contrapondo o dêitico aqui - acampamento - com lá - cidade -, sendo que ambos situam o sujeito discursivo no espaço, verifica-se que o primeiro refere-se ao espaço adequado para se estabelecer socialmente, tanto é certo que os produtos obtidos nesse lugar podem ser transportados para aquele (a cidade), assegurando as condições existenciais às pessoas que lá se encontram.

Ao enumerar a produção alimentícia (farinha, polvilho, mandioca, verdura) obtida no acampamento, contraposta à sua precariedade na cidade, o enunciador evidencia a sua reconstrução como sujeito, antes desconstruído naquele espaço.

O espaço urbano é considerado tão inadequado para/pelos os sujeitos, agora denominados Sem-Terra, que até mesmo os que emigraram para a cidade levando algum bem material caminharam rumo à penúria, conforme se pode notar com a leitura do fragmento anterior. Essa inadaptação deve-se à constituição sociocultural e 
discursiva dos sujeitos em outros espaços sociais, dissonantes do que passaram a ocupar.

As referências a espaço e tempo no discurso explicita a inserção dos sujeitos em diferentes momentos na História do Brasil marcados pelas seguintes passagens: o espaço rural como produtivo para o lavrador, as mudanças nas condições de produção para esse sujeito, o espaço urbano como propício à decadência, a aparição dos movimentos de luta pela terra. Nesses momentos historicamente marcados, os sujeitos situam-se no tempo por meio do discurso e evidenciam as tentativas de reintegração a formas de produção praticamente já abolidas. Em alguns casos, a dificuldade para o estabelecimento social nesse novo mundo, o citadino, leva os sujeitos a tentar reproduzir nele suas formas de existência, seus hábitos, valores socioculturais originais.

De uma maneira genérica, o deslocamento do lavrador para a cidade, futuro Sem-Terra, evidencia dois mundos em contraste. Nesses mundos, confrontam-se também a forma de existência social dos sujeitos que o integram, e formam-se discursos do/sobre o SemTerra em conformidade com as transformações histórico-sociais observadas. Notam-se, nesses contrastes que possibilitam formações discursivas, diferentes formas de construção e destruição dos sujeitos, conforme se discutiu anteriormente. Esses contrastes sociais presentes, caracterizando o discurso do Sem-Terra, receberão atenção especial no próximo tópico.

\section{Contrastes campo $x$ cidade}

Odiscurso doSem-Terracaracteriza-se porcontrastes, poroposições próprias às contraposições sociais constitutivas desses sujeitos. Nesse sentido, contrastam-se mundos socioculturais nos quais têm existência. Desses mundos, destacam-se, de maneira genérica, o rural e o urbano com suas próprias condições histórico-sociais de produção (de trabalho, de comportamento, de ideologia e de discursos).

Apontou-se, anteriormente, que o deslocamento do espaço rural para o urbano decorre da desconstrução do sujeito naquele espaço em busca da sua reconstrução sob novas condições socioculturais. No entanto, verificou-se a existência de um sujeito destituído socialmente na cidade, que se deslocou no espaço físico e social, sem, contudo, assegurar mudanças em sua condição existencial, visto que sua produção material não sofreu alterações. 
Diante dessas questões, a análise dos fragmentos a seguir focaliza as contradições entre esses dois espaços tendo em vista as condições de existência dos sujeitos em observação.

\section{Fragmento 5}

É ... é que geralmente esse pessoal que tá aqui é pessoal que foi... que todo mundo é gente que veio da roça mesmo ... aqui quem dá ... é ... que foi nascido na cidade é pouca gente ... é só essas pessoas mais novas só essas mais criança mesmo ... o resto é maioria da idade minha pra cima é tudo gente que veio foi da roça mesmo nascido na roça ... eles mora na cidade mais eu acredito ... deve nasceu na cidade mais morou muito tempo na roça... né ... intão ... nois tamo quereno chegá a esse ponto porque nós todo temo custume com o trabalho ... aqui vamo dizê assim tudo ... é gente que sabe o que é o sirviço da roça (S1/p.13)

Nesse fragmento, verifica-se que o enunciador situa-se pragmaticamente no discurso por meio do dêitico aqui (elemento lingüístico que localiza o sujeito no espaço - acampamento - e indica o aspecto temporal - presente). Ao fazer referência à pessoa, o enunciador engloba o grupo dos sujeitos a que pertence - todo mundo - apontando as suas origens e, em consequiência, as preferências e habilidades para o trabalho. A cidade é considerada como o lugar estranho a seus hábitos, já a roça apresenta-se, além de espaço físico, como o espaço sociocultural em que os sujeitos se constituíram. Acentua-se, dessa maneira, a fragmentação dos sujeitos, a heterogeneidade constitutiva do Sem-Terra, cuja definição resulta da experimentação de diferentes aspectos socioculturais por lugares onde viveram. A interação social desses sujeitos, considerando as condições de produção experimentadas, possibilitou-lhes diferentes formações ideológicas e discursivas na definição (ou indefinição) do Sem-Terra, ser marcado por instabilidade.

Ao final do fragmento em observação, o enunciador, quando afirma nois tamo quereno chegá a esse ponto, refere-se à reconstrução social das suas origens, do espaço rural socialmente estruturado no qual implementarão suas formas de trabalho, suas condições de produção. $\mathrm{O}$ trabalho é considerado como o elemento fundamental para assegurar formas de exercício da cidadania, formas dignas de pertença à sociedade.

De uma maneira geral, os Sem-Terra expressam o desejo de reestruturação social. Observando-se, nas entrevistas, as referências à reforma agrária, verificam-se formações discursivas, visto que, ao 
apontar a reforma agrária como solução para os problemas de âmbito nacional, presentifica-se um discurso ideologicamente marcado, oriundo de uma consciência política própria a partidos denominados esquerdistas, cujas pautas reivindicatórias firmam-se nas possibilidades de reestruturação social, em oposição às forças hegemônicas vigentes. As reformulações apontadas como possíveis implicam divisões do que há em excesso no tocante a bens materiais, centralizados nas mãos de alguns, visando à construção de uma sociedade mais igualitária.

Nessa perspectiva, as fazendas apontadas como improdutivas, terras muitas vezes inacessíveis a possíveis trabalhadores rurais, constituem ponto de debate, elemento eliminador possível da miséria humana. Como formação de um discurso, destaca-se a re-significação da cidade para o lavrador - lugar de onde se distancia: lá -, que, ao se tornar seu habitante, reconheceu-a como um espaço inadequado, contrariando as perspectivas que o levaram à imigração.

A produção do próprio sustento é indicada como a única possibilidade de sobrevivência; surge então a necessidade do acesso à terra, cuja posse é vista como asseguradora da libertação da opressão experimentada na cidade.

Esses apontamentos resultam das referências a espaços nos fragmentos analisados, como se pode ratificar: a cidade, espaço físico e social, que impõe precárias condições existenciais ao lavrador; o Brasil, cuja estruturação social se caracteriza por desigualdades que, segundo o Sem-Terra, podem ser amenizadas com a reforma agrária. Relacionadas às indicações espaciais, encontram-se as referências a tempo apresentando o presente - hoje - como o momento para a construção do futuro, como pode ser notado no fragmento seguinte.

\section{Fragmento 6}

é assim... purque hoje as mulheres de hoje da cidade elas acha custoso cuzinhá no fugão de lenha ... acha custoso purque num tem uma sombra pode queimá é ... agora nois que tá aqui nois num acha que não ... acha que a vida da mulher tem que sê essa ... purque desde que eu intendo pur gente ... minha mãe era do campo é falicida mais ela insinô isso pra gente e eu acho que aqui a gente é livre ... cê tem a sua lenhinha pra cozinhá pa cumê assim talveiz é mais gostoso é ... intão nois acha que ... e num acho custoso a luta aqui sobre a mulher cuzinhá lavá talveiz uma rôpa num corgo quando num tem cisterna ô tirá água na cisterna eu num acho custoso isso não eu acho q'isso faiz parte da vida e isso Deus deixô desde o cumeço da criação né pra gente lutá ... é o que tem pa te falá (S2/p.22) 
$\mathrm{O}$ enunciador inicia situando-se no tempo presente da entrevista - hoje - a partir do qual estabelece contraste entre as condições de vida nos diferentes espaços físico-sociais em observação. Em seguida, emprega o dêitico espacial aqui, que evidencia sua situação social. Referindo-se especificamente às atividades executadas por mulheres, explicita os recursos materiais nos diferentes lugares. Destaca, nesse aspecto, a inexistência do fogão a gás no acampamento relacionando a este utensílio doméstico hábitos entre pessoas integrantes de diferentes mundos. As mulheres citadinas não se dispõem a cozer sem a utilização desse objeto, enquanto, para a acampada entrevistada, não se apresenta como uma necessidade básica. Ainda mais: defende que a mulher deve se submeter à utilização de recursos primários e precários para a sobrevivência, tais como o fogão a lenha, resgatando, nessa perspectiva, suas origens, como se pode apreender pela seguinte referência temporal: desde que eu intendo por gente.

Acredita-se, contudo, nesta pesquisa, que o anseio da entrevistada acima se deve à situação social marcada por penúria em que se encontra e, uma vez asseguradas as necessidades de produção e reprodução alimentares, esses sujeitos reivindicarão, como necessidades básicas, os recursos materiais que facilitam e viabilizam melhores condições para realização do trabalho. Porém, a utilização da lenha para cozinhar vincula-se também ao sabor dos alimentos preparados, como afirma: cê tem a sua lenhinha pra cozinhá pa cumê assim talveiz é mais gostoso. Esse aspecto relaciona-se aos hábitos antigos, anteriores mesmo à criação e difusão do fogão a gás, e ainda encontrados em alguns ambientes rurais, que, certamente, os Sem-Terra procuram resgatar.

Ao situar-se no espaço presente mediante o dêitico aqui, o acampamento é apresentado como o lugar propício à liberdade, onde poderão colocar em prática arraigadas formas socioculturais experimentadas nos primeiros anos de suas vidas, em um espaço do qual foram excluídos. Confrontos, constantes confrontos marcam a forma de existência desses sujeitos.

A análise desenvolvida possibilita, de uma maneira geral, destacar dois aspectos como os maiores responsáveis pelo desejo de retorno ao campo. Além da unânime rejeição à cidade, em busca da reconstrução dos valores socioculturais perdidos, fato que constitui o segundo aspecto, há, em primeira instância, a necessidade do estabelecimento das condições de produção adequadas à sobrevivência, destacando-se como primordial a produção alimentícia. 
Contudo, dado o acentuado caráter de instabilidade experimentado, é a cidade o lugar ideal para o estabelecimento de interações que favorecem as formações discursivas, pelas mudanças nas perspectivas ideológicas que possibilitam a formação de um grupo de sujeitos afins e a organização do grupo para o ingresso à luta. Nas cidades, ocorrem rearticulações de base política mediante práticas discursivas levando a ações que contrariam as forças hegemônicas e os interesses políticoeconômicos da burguesia.

Os Sem-Terra entrevistados demonstram reconhecer as renovações na estruturação da sociedade, as criações das leis trabalhistas e as exigências de seus cumprimentos como elementos dificultadores aos trabalhadores rurais dependentes de proprietários de terra para garantir as próprias condições de produção. Acrescenta-se a esses questionamentos o retorno involuntário ao espaço rural na condição de Sem-Terra, pois, não havendo possibilidade de produção agrícola em terras alheias, e não sendo possível estabelecer-se socialmente na cidade, resta-lhe, como último recurso, a luta pela conquista da terra, única maneira de assegurar a produção do próprio sustento e reintegrar-se à sociedade.

A cidade é, portanto, o palco das articulações políticas que acentua as formações ideológicas manifestas nas formações discursivas. Como resultado, o grupo de sujeitos articulados, autodenominado Sem-Terra, desloca-se para uma propriedade agrícola considerada improdutiva, formando o acampamento. O espaço sociocultural rejeitado, a cidade, é também constitutivo dos sujeitos em questão e, nele, se dá a formação discursiva do Sem-Terra constituída por diferentes elementos que têm lugar na História.

\section{CONSIDERAÇÕES FINAIS}

O discurso do Sem-Terra, situado histórica e socialmente, constitui uma forma de ação social. A explicitação dos sentidos do discurso implicou compreender as condições de produção desse discurso, pois trata-se dos sentidos das enunciações produzidas no contexto de luta em que os sujeitos encontram-se. Eis, então, um entrecruzamento necessário da Lingüística com a História, para a compreensão dessa formação discursiva.

A recorrência à História faz-se presente na análise do discurso do Sem-Terra, pois trata-se dos sentidos produzidos no discurso, de acordo com as condições de produção histórico-sociais peculiares à existência desses sujeitos. 
Contrapondo-se a uma abordagem a-histórica, a Análise do Discurso, ao refletir sobre as condições histórico-sociais que envolvem a produção do discurso, recorre à História, visando a analisar o material em termos de produções localizáveis em um lugar sócio-histórico (lugar de produção socioeconômico, político-ideológico e cultural). As indagações organizam-se em função desse lugar. A relação com o corpo social é precisamente o objeto da História (DE CERTEAU, 1979, p. 22).

Essa contribuição apresenta-se fundamental para o estudo do discurso do Sem-Terra, visto que, tomando o discurso como objeto de análise, procurou-se compreender a constituição do sujeito SemTerra, a constituição do grupo social desses sujeitos e suas formações discursivas. Para tal empreendimento, buscou-se resgatar as suas origens socioculturais ${ }^{2}$, observaram-se suas transformações expressas principalmente pelas condições de realização do trabalho e pela produção econômica em diferentes momentos, bem como suas formações e transformações ideológicas nas interações sociais. A transformação social desejada passaria por uma ruptura com as formações discursivas próprias às forças hegemônicas, às quais se encontravam submissos. A noção de formação discursiva engloba todos esses elementos, perpassando por diferentes áreas de estudo. Em tese, houve uma trajetória de deslocamentos sem rupturas. Transfere-se de um espaço de enunciação a outro, mas mantém-se a unidade dos discursos pela dispersão de objetos, temas e sujeitos evidenciados pela análise.

As alterações político-ideológicas observadas no discurso resultam das mudanças sofridas pelos sujeitos em cena, isto é, da transformação dos sujeitos na linha do tempo, que demandou mudanças no espaço

${ }^{2} \mathrm{O}$ desejo de restabelecimento de uma cultura original, expresso pelos SemTerra, implica mudanças significativas no quotidiano e envolve várias atividades. Estas iniciam-se com o horário de despertar, em muitos casos, às cinco horas da manhã, quando o trabalho de campear o gado bovino para colher o leite ainda para o café da manhã marca o início do dia; em seguida, procede-se à recondução do gado à pastagem; à alimentação dos suínos e das aves domésticas. Ao longo do dia, geralmente, há a execução de algum trabalho agrícola com a utilização de ferramentas como machado, foice, enxada etc. Atividades como a preparação da terra para o plantio de sementes, a capina da lavoura, momento em que se separa o joio do trigo, preenchem o cotidiano dessa gente. O horário reservado às refeições difere-se dos habituais citadinos: o almoço é servido, no mais tardar, às onze horas, e o jantar às dezoito. Ao final da tarde, ainda há tempo para se sentar na cerca do estábulo e, empunhando fumo e palha às mãos calejadas, tecer o próprio cigarro.

Faculdade de Letras | Universidade de Coimbra 
social. A interação dos Sem-Terra na sociedade, considerada de maneira ampla, provocou formações de novos discursos concomitantes com as mudanças políticas, ideológicas e culturais sofridas por esses sujeitos. $\mathrm{Na}$ verdade, novas perspectivas políticas e ideológicas implicaram o surgimento de um novo cenário sociocultural na História, desencadeando a formação de discursos. Houve alterações nas condições de produção de discurso e de ideologia, das quais as formações discursivas são resultantes. Os sentidos formam-se na história.

Os discursos são construídos socialmente pela interação entre os sujeitos sociais organizados, ao mesmo tempo em que têm a propriedade de construir as interações sociais. Esta análise abordou o conteúdo semântico, tendo em vista os aspectos socioculturais, políticos e ideológicos presentes nas negociações de sentidos constitutivas da formação discursiva do Sem-Terra. O Sem-Terra não integra uma condição social estável, ao contrário, constitui um grupo social marcado por instabilidades, por contradições, cuja constituição social tem um caráter transitório, representa uma passagem na vida dos sujeitos, e o discurso constitui ação social integrando as atividades dos sujeitos em questão. Como ação, a prática discursiva apresenta-se como um instrumento utilizado nos confrontos com as forças hegemônicas, contrárias aos movimentos dos trabalhadores rurais Sem-Terra.

A Análise do Discurso é palavra em movimento, fazendo aparecer e desaparecer as contradições que, contraditoriamente, asseguram a coerência das ações sociais que preenchem o cotidiano do grupo de sujeitos Sem-Terra.

Quanto à interlocução, o diálogo, dos Sem-Terra com grupos de apoio e grupos contrários (militantes oriundos de sindicatos, religiões, partidos políticos, forças represálias) inscritos em diferentes formações discursivas, verificou-se que a ideologia é o aspecto constitutivo dos diferentes discursos e esse dialogismo possibilitou a constituição de um discurso específico do Sem-Terra, preenchido pelas formações ideológicas que lhes são próprias. Tratam-se transformações históricas nas quais se mesclam diferentes discursos inscritos em formações ideológicas que se contradizem e dispersam. Em concomitância com as formações e transformações discursivas, os sujeitos constituem-se marcados por heterogeneidades. Todos esses elementos integram os sentidos das enunciações dos Sem-Terra produzidas no campo e na cidade.

Os sujeitos acampados transformam-se ideológica e discursivamente imputando em seus discursos o reconhecimento do direito à cidadania, o direito de pertença à sociedade pela inclusão e/ou absorção 
de elementos e termos, cujos sentidos inscrevem-se nas formações discursivas político-socialistas, pautam-se em sentidos produzidos por expressões de caráter legalista e legalizador e, para tanto, sofrem as (trans)formações discursivas que desencadearam o Sem-Terra.

\section{Bibliografia}

De CERTEAU, M. A Escrita da História. Rio de Janeiro: Forense Universitária, 1982.

. A Operação Histórica. In: LE GOFF, J. \& NORA, P. História: Novas Problemas. Rio Janeiro: Livraria Francisco Alves Editores S. A., 1979.

FERNANDES, C. A. Interação Social e Formação Discursiva no Movimento de Luta pela Terra. Tese de Doutoramento. São Paulo: FFLCH/USP, 2001. (mimeo).

FOUCAULT, M. Arqueologia do Saber. São Paulo: Forense Universitária, 1995.

GUILHAUMOU, J. "Os Historiadores do discurso e a noção conceito de formação discursiva: narrativa de uma transvaliação imanente". In: Revista Ecos. Cuiabá: EDUNEMAT, Ano III, n 3, 2005. p. 107-115.

LAHUD, M. A Propósito da Noção de Dêixis. São Paulo: Ática, 1979.

MAINGUENEAU, D. O Contexto da obra literária. São Paulo: Martins Fontes, 1995.

ORLANDI, E. P. et al. Vozes e Contrastes: Discurso na Cidade e no Campo. São Paulo: Cortez, 1989.

PÊCHEUX, M. "A Análise do Discurso: Três Épocas (1983)". In: GADET, F. \& HAK, T. Por uma Análise Automática do Discurso: Uma Introdução à Obra de Michel Pêcheux. Campinas: EDUNICAMP, 1990. (pp. 311-319).

ROBIN, R. História e Lingüística. São Paulo: Cultrix, 1973.

SILVA, L. M. R. Os Trabalhadores em Luta pela Terra no Triângulo Mineiro: 1989/1996. São Paulo: Pontifícia Universidade Católica de São Paulo, 1996. Dissertação de Mestrado. (mimeo).

VOESE, I. O Movimento dos Sem-Terra na Imprensa: um exercício de análise do discurso. Ijuí, RS: EDUNIJUÍ, 1998. 